\title{
Mass spectrometry of some arylidene thioxobenzyl or thioxobiphenyloxoethyl thiazolidinone compounds
}

\author{
V.L.M. Guarda ${ }^{a}$, C. Bosso ${ }^{\text {b }}$, S.L. Galdino ${ }^{\text {a }}$, J.F.C. Albuquerque ${ }^{\text {a }}$, M.C.A. Lima ${ }^{\text {a }}$, \\ J.B.P. Silva ${ }^{a}$, L.F.C. Leite ${ }^{\mathrm{a}}$ and I.R. Pitta ${ }^{\mathrm{a}}$ \\ ${ }^{\text {a }}$ Grupo de Pesquisa do Laboratório de Planejamento e Síntese de Fármacos, Universidade Federal de \\ Pernambuco, Cidade Universitária, CEP 50670-901 Recife, Brasil \\ ${ }^{\mathrm{b}}$ Centre de Recherches sur les Macromolécules Végétales - CERMAV - CNRS, BP 53X, 38041 \\ Grenoble cédex, France
}

\begin{abstract}
This paper reports the results of a comparative study of the electron impact mass spectrometry data for a series of previously synthetized 5-arylidene-3-(4-chloro-benzyl)-4-thioxo-thiazolidin-2-one, and 5-arylidene-3-(2-biphenyl-4-yl-2-oxoethyl)-4-thioxo-thiazolidin-2-one derivatives. Theoretical calculations of molecular mechanics, MOPAC-AM1, were used to explain the fragmentations observed.
\end{abstract}

Keywords: Mass spectra, thiazolidinones

\section{Introduction}

We recently reported the fragmentation routes of other chlorobenzyl imidazolidinedione and fluoro or chlorobenzyl thiazolidinedione compounds [1].

The mass spectrometry in positive- and negative-ion mode has also been reported for a series of 5arylidene-3-chloro-benzyl-imidazolidine-2,4-dione and thiazolidine-2,4-dione derivatives [2].

Nonsteroidal antiinflammatory drugs (NSAIDs) are the most used in the tratment of inflammatory disease and are amog the most widely used drugs. Thiazolidines appears in scientific papers as substances with great biological activity, including anti-inflammatory [3]. The thiazolidinediones (TDZs), also called glitazones or gitazones, are equally known to be insulin sensitizers and have been developed and used clinically as anti-diabetes agents [4]. It is now known that the molecular target of the thiazolidinediones is associated with a nuclear receptor called PPARg (peroxisome proliferator-activated receptor) [5,6].

Synthesis of some 5-benzylidene-thioxoimidazolidinones and thioxothiazolidinones substituted at the position 3 by benzyl or phenacyl group, were reported in previous papers [7-10].

This paper reports the results of a study of electron-impact mass spectrometry in positive-ion mode of a series of 5-arylidene-3-(4-chloro-benzyl)-4-thioxo-thiazolidin-2-one and 5-arylidene-3-(2-biphenyl-4yl-2-oxo-ethyl)-4-thioxo-thiazolidin-2-one derivatives and possible fragmentation routes are outlined. 


\section{Experimental}

The 5-arylidene-3-(4-chloro-benzyl)-4-thioxo-thiazolidin-2-one 1-9 were prepared by reacting thiazolidine-2,4-dione with 4-chloro-benzyl chloride in alkaline conditions. The action of the phosphorus pentasulphure allows 3(4-chloro-benzyl)-4-thioxo-thiazolidin-2-one to be produced. The condensation of these 3-substituted compounds with benzaldehydes gave the corresponding thiazolidinones [11].

The 5-arylidene-3-(2-biphenyl-4-yl-2-oxo-ethyl)-4-thioxo-thiazolidin-2-one compounds 10-19 were prepared by reacting thiazolidine-2,4-dione with phosphorus pentasulphure followed by condensation with benzaldehydes. The alkylation in position-3 with 2-bromo-1-phenyl-ethanone in alkaline conditions produced the corresponding thiazolidinone compounds [12].

The electron-impact mass spectra are recorded on a R-1010C DELSI-NERMAG mass spectrometer by direct introduction at a nominal electron energy of $70 \mathrm{eV}$, a source temperature of $205^{\circ} \mathrm{C}$ and an emission current of $0.150 \mathrm{~mA}$. The samples were volatilized in the source with temperature increasing from 30 to $300^{\circ} \mathrm{C}$ at the rate of $2^{\circ} \mathrm{C}$ per second.

\section{Results and discussion}

The 5-arylidene-3-(4-chloro-benzyl)-4-thioxo-thiazolidin-2-one derivatives 1-9 show an intense molecular ion peak, with the exception of compounds $\mathbf{2}$ and $\mathbf{5}$ which are substituted by fluorine in position- $2 \mathrm{M}^{+\cdot} 363(7.4 \%)$ or by chlorine in positions-2,4 $\mathrm{M}^{+\cdot} 413(1.3 \%)$. When thiazolidinones have a biphenyloxoethyl radical in position-3 of the heterocyclic ring, the molecular ion peaks are lower than $1 \%$ for all the compounds studied.

In every case the principal fragmentation for arylidene thioxobenzyl thiazolidinones 1-9 is the cleavage of the side chain in position-3 producing the ion $m / z 125\left(4-\mathrm{ClC}_{6} \mathrm{H}_{4} \mathrm{CH}_{2}^{+}\right)$accompanied by the expulsion of $\mathrm{HCl}$ and acetylene and leading to the formation of the ions $m / z 89, m / z 99$ and $\mathrm{m} / z 63$ $[2,13]$. The other fragmentations of these compounds involve the degradation in heterocyclic ring by way of two important cleavage processes. The first route of the degradation pattern, previously reported by Pitta et al. [2] for some analogous compounds, leads to the $\alpha$-ion. The second route is formed by the double cleavage of the $\mathrm{N}_{3}-\mathrm{C}_{4}$ and $\mathrm{S}_{1}-\mathrm{C}_{2}$ single bonds leading to the $\beta$-ion. For these compounds the $\beta$-ion loses the substituant of the phenyl ring giving the ions $\beta$-R. The relative abundance of these fragments are reported in Table 1 and the degradation pattern are summarized in Fig. 1.

In the arylidene thioxobiphenyloxoethyl thiazolidinone compounds 10-19, reported in Table 2, fragmentations probably leading to the ions $\alpha \mathrm{m} / z 152$ and $\beta \mathrm{m} / z 196(9.8 \%$ and $13.3 \%)$ were observed for the 17 and 18 compounds, substituted by a fluorine atom in positions ortho or para in the radical arylidene. These thiazolidinone compounds substituted by thioxobiphenyloxoethyl group in the 3-position of heterocyclic ring, show the ion $m / z 181\left(4-\mathrm{C}_{6} \mathrm{H}_{5} \mathrm{C}_{6} \mathrm{H}_{4} \mathrm{CO}^{+}\right)$, formed by the cleavage of the $\mathrm{C}_{6}-\mathrm{C}_{7}$ single bond, as the preferred fragmentation route. The biphenylacylium ion base peak of these compounds loses carbon monoxide to give the ion $m / z 153$. This fragment follows two specific degradation routes leading to the formation of ions $m / z 77\left(\mathrm{C}_{6} \mathrm{H}_{5}^{+}\right)$and ion $m / z 127$ respectively through loss of an acetylene molecule. The degradation pattern of these compounds are summarized in Fig. 2.

The biphenylacylium ion formed by the rupture of the lateral chain is the base peak for the thiazolidinones 10-19 with the exception of the 3-(2-biphenyl-4-yl-2-oxo-ethyl)-5(4-fluorobenzylidene)-4thioxo-thiazolidin-2-one $\mathbf{1 8}$ compound which showed a similar base peak, the fragment $m / z 152$ being formed by the degradation of the side chain or by type $\alpha$ degradation of the thiazolidine ring. 


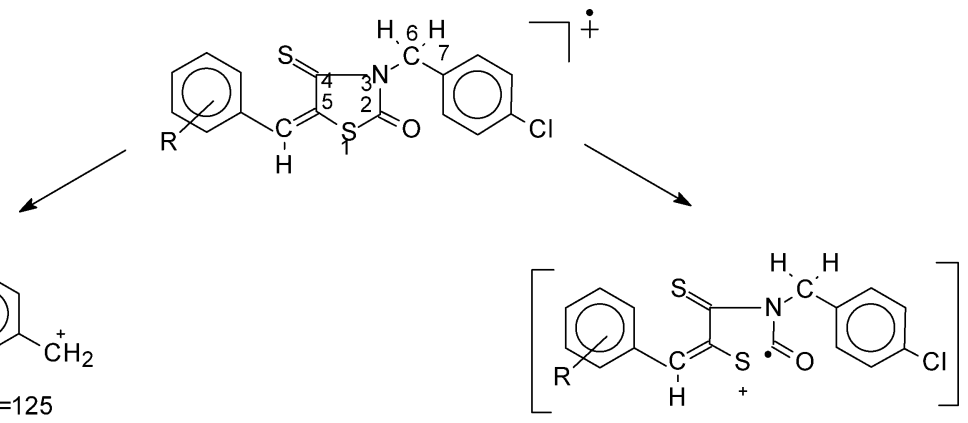

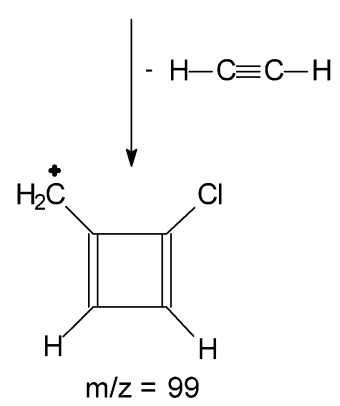

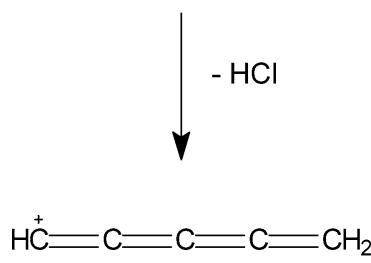

$\mathrm{m} / \mathrm{z}=63$
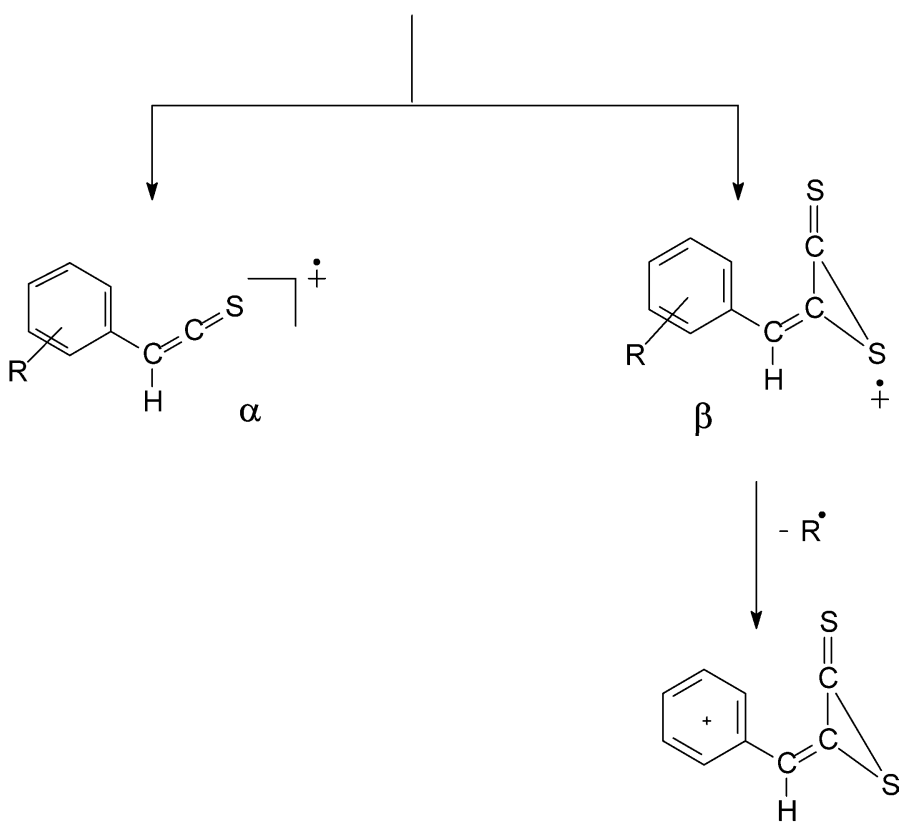

$\beta-\mathbf{R}$

Fig. 1. Schematic representation of the route for the thioxobenzyl arylidene thiazolidinones compounds 1-9.

Table 1

Characteristic peaks for compounds 1-9

\begin{tabular}{lllccll}
\hline $\mathrm{N}^{\circ}$ & $\mathrm{R}$ & \multicolumn{5}{c}{ Ions $m / z(\mathrm{I} \%)$} \\
\cline { 3 - 6 } & & \multicolumn{1}{c}{$\mathrm{M}^{+}$} & $m / z 125$ & $\alpha$ & $\beta$ & $\beta-\mathrm{R}$ \\
\hline $\mathbf{1}$ & $\mathrm{H}$ & $345(100)$ & 83.6 & $134(34.3)$ & $178(38.6)$ & $177(28.9)$ \\
$\mathbf{2}$ & $2-\mathrm{F}$ & $363(7.4)$ & 100 & $152(13.2)$ & $196(2)$ & $177(1.1)$ \\
$\mathbf{3}$ & $4-\mathrm{F}$ & $363(90.1)$ & 100 & $152(52.3)$ & $196(25.8)$ & $177(3.7)$ \\
$\mathbf{4}$ & $4-\mathrm{Cl}$ & $379(65)$ & 100 & $168(16.3)$ & $212(6.6)$ & $177(40.7)$ \\
$\mathbf{5}$ & $2,4-\mathrm{Cl}_{2}$ & $413(1.3)$ & 100 & $202(1.8)$ & $246(0.2)$ & $211(4.3)$ \\
$\mathbf{6}$ & $4-\mathrm{OCH}_{3}$ & $375(100)$ & 64 & $164(24.1)$ & $208(14.9)$ & $177(33.2)$ \\
$\mathbf{7}$ & $2,4-\mathrm{OCH}_{3}$ & $405(20)$ & 100 & $194(11.7)$ & $238(0.6)$ & $207(7.2)$ \\
$\mathbf{8}$ & $3,4,5-\mathrm{OCH}_{3}$ & $435(36)$ & 100 & $224(10.6)$ & $268(2.6)$ & $237(20.3)$ \\
$\mathbf{9}$ & $2-\mathrm{CH}_{3}$ & $359(25.8)$ & 99.7 & $148(10.6)$ & $192(7.5)$ & $177(20.5)$ \\
\hline
\end{tabular}




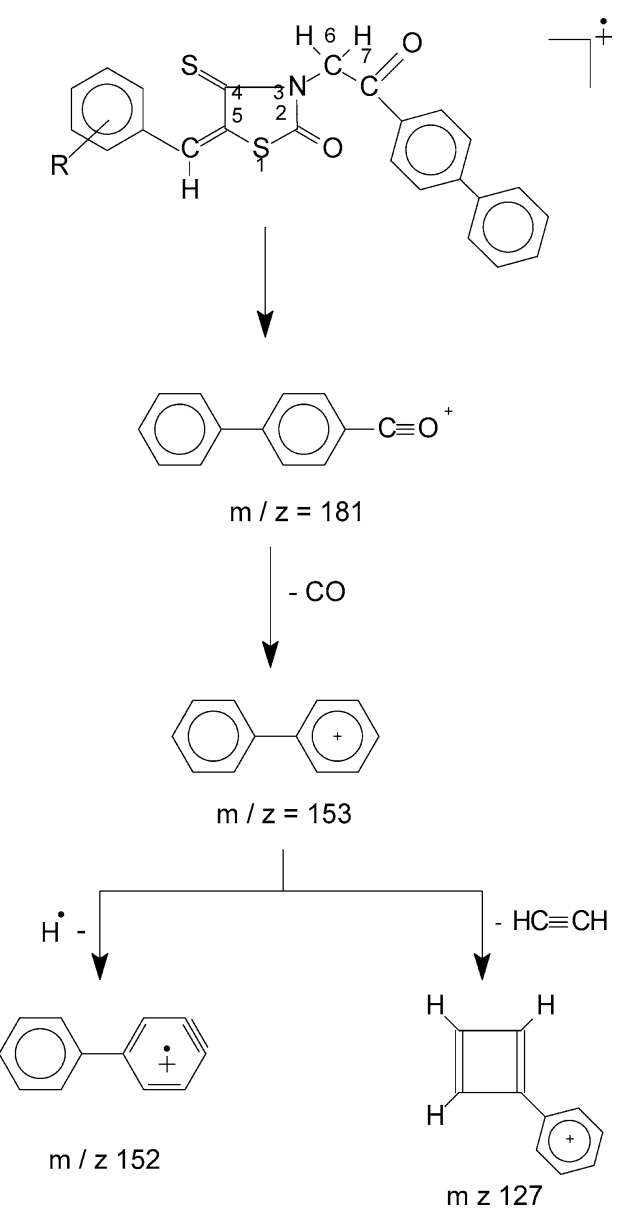

Fig. 2. Schematic representation of the route for the thioxophenylphenacyl arylidene thiazolidinones compounds 10-19.

Table 2

Characteristic peaks for compounds 10-19

\begin{tabular}{|c|c|c|c|c|c|c|}
\hline \multirow[t]{2}{*}{$\overline{N^{\circ}}$} & \multirow[t]{2}{*}{$\mathrm{R}$} & \multicolumn{5}{|c|}{ Ions $m / z(\mathrm{I} \%)$} \\
\hline & & $\mathrm{M}^{+}$ & $m / z 181$ & $m / z 152$ & $m / z 153$ & $m / z 127$ \\
\hline$\overline{10 *}$ & $\mathrm{H}$ & $415(1.51)$ & 71.9 & 73.1 & 79.2 & 13.5 \\
\hline $11 * *$ & $4-\mathrm{Cl}$ & 449 (1) & 100 & 15.9 & 9.5 & 2.5 \\
\hline 12 & $2-\mathrm{Cl}$ & $449(0.1)$ & 100 & 47.4 & 24 & 5.9 \\
\hline 13 & $3-\mathrm{Cl}$ & $449(0.11)$ & 100 & 53.9 & 28.4 & 7.4 \\
\hline 14 & $3,4-\mathrm{Cl}_{2}$ & $483(0.03)$ & 100 & 49.4 & 24 & 5.7 \\
\hline 15 & $2-\mathrm{Br}$ & $493(0.64)$ & 100 & 62.2 & 27.9 & 10.8 \\
\hline $16^{* *}$ & $3-\mathrm{Br}$ & $493(0.61)$ & 100 & 16.8 & 9.3 & 1.8 \\
\hline 17 & $2-\mathrm{F}$ & $433(0.55)$ & 100 & 82.2 & 35.9 & 8.8 \\
\hline 18 & $4-\mathrm{F}$ & $433(0.9)$ & 94.7 & 100 & 31.1 & 8.6 \\
\hline 19 & $4-\mathrm{OCH}_{3}$ & $445(0.03)$ & 100 & 54.1 & 26.6 & 7.9 \\
\hline
\end{tabular}

$* m / z 182(100 \%), m / z 153(79.2 \%)$.

$* *$ ci $\mathrm{NH}_{3}+$ isobutane. 
Table 3

Charge densities in doublet state of the atoms $\mathrm{N}_{3}, \mathrm{C}_{6}$ and $\mathrm{C}_{7}$ for compounds 1-19

\begin{tabular}{lccccccccccc}
\hline $\mathrm{N}^{\circ}$ & $\mathrm{N}_{3}$ & $\mathrm{C}_{6}$ & \multicolumn{1}{c}{$\mathrm{C}_{7}$} & $\mathrm{~N}^{\circ}$ & \multicolumn{1}{c}{$\mathrm{N}_{3}$} & \multicolumn{1}{c}{$\mathrm{C}_{6}$} & \multicolumn{1}{c}{$\mathrm{C}_{7}$} & $\mathrm{~N}^{\circ}$ & $\mathrm{N}_{3}$ & $\mathrm{C}_{6}$ & $\mathrm{C}_{7}$ \\
\hline $\mathbf{1}$ & -0.260 & 0.011 & -0.174 & $\mathbf{7}$ & -0.262 & 0.013 & -0.183 & $\mathbf{1 3}$ & -0.255 & -0.082 & 0.251 \\
$\mathbf{2}$ & -0.260 & 0.010 & -0.173 & $\mathbf{8}$ & -0.264 & 0.014 & -0.173 & $\mathbf{1 4}$ & -0.255 & -0.084 & 0.261 \\
$\mathbf{3}$ & -0.260 & 0.010 & -0.173 & $\mathbf{9}$ & -0.260 & 0.011 & -0.175 & $\mathbf{1 5}$ & -0.255 & -0.084 & 0.251 \\
$\mathbf{4}$ & -0.260 & 0.010 & -0.173 & $\mathbf{1 0}$ & -0.257 & -0.082 & 0.263 & $\mathbf{1 6}$ & -0.255 & -0.084 & 0.262 \\
$\mathbf{5}$ & -0.260 & 0.011 & -0.172 & $\mathbf{1 1}$ & -0.257 & -0.082 & 0.263 & $\mathbf{1 7}$ & -0.255 & -0.084 & 0.25 \\
$\mathbf{6}$ & -0.261 & 0.010 & -0.177 & $\mathbf{1 2}$ & -0.256 & -0.083 & 0.263 & $\mathbf{1 8}$ & -0.255 & -0.084 & 0.251 \\
& & & & & & & & $\mathbf{1 9}$ & -0.255 & -0.084 & 0.254 \\
\hline
\end{tabular}

A survey using theoretical calculations of molecular mechanics was conducted with the aim of demonstrating the importance of using a combination of experimental and theoretical studies in order to understand and identify the structural characteristics that enable the explanation of the fragmentation mechanism observed in the mass spectrometry.

When fragmentation occurs as a result of electron impact the probability of a bond breaking is related to the strength of the bond, the possibility of low energy transfer and the stability of the neutral and charged fragments formed by the process.

Molecular mechanics was used in this work, with the aid of the Chemoffice (Version 5.0) computer program and ChemDraw Ultra to generate the structures of the compounds and Chem3D Pro for preliminary geometrical optimization. The compounds were optimized using method AM1 of the MOPAC program.

The series of arylidene thioxobenzyl thiazolidinones 1-9 and arylidene thioxobiphenyloxoethyl thiazolidinone compounds 10-19, were submitted to two types of calculation. Firstly the AM1 method was used, with the keywords: AM1 PRECISE, VECTOR, FORCE, MMOK, Gnorm $=0.5$ and the values of the formation heat, bond length and the density of charge of the atoms were recorded for each compound. Shortly afterwards, each of the compounds was submitted to a new calculation using the same procedure mentioned above and the additional keyword: DOUBLET, CHARGE $=+1$, since, under electron impact, the compounds lose an electron generating the ion cation or the ion-radical.

To solve the problem of configuration around the double bond ethylenic, the two possible $\mathrm{Z}$ and $\mathrm{S}$ diastereoisomers were treated by the MOPAC program/AM1. For all compounds it was observed that the $\mathrm{Z}$ isomer exhibits a formation heat lower than that of the $\mathrm{E}$ isomer. These results show that the $\mathrm{Z}$ isomer is thermodynamically the stabler. The potential for ionization shows that the $\mathrm{Z}$ isomer has a greater capacity to free its electrons, thereby endowing it with greater stability.

With regard to the formation of ions and their fragmentation mechanisms, on electron impact, the values for the charge densities of the atoms (Table 3) and for bond lengths (Table 4) may indicate their mode of formation.

The analysis of the charge density of the atoms $\mathrm{N}_{3}, \mathrm{C}_{6}$ and $\mathrm{C}_{7}$ in the side chain situated in position-3 for (Z) arylidene thioxobenzyl thiazolidinones 1-9 compounds shows that cleavage of this side chain giving the ion $m / z 125\left(4-\mathrm{ClC}_{6} \mathrm{H}_{4} \mathrm{CH}_{2}^{+}\right)$, is justified by the largest concentration of negative charge in the nitrogen atom. In the 1 compound the difference in density of charge between $\mathrm{N}_{3}$ and $\mathrm{C}_{6}$ is 0.271 while for $\mathrm{C}_{6}$ and $\mathrm{C}_{7}$ it is 0.185 . For $(\mathrm{Z})$ arylidene thioxobiphenyloxoethyl thiazolidinone compounds 10-19 observation of the charge density of the atoms $\mathrm{N}_{3}, \mathrm{C}_{6}$ and $\mathrm{C}_{7}$ shows that the difference in charge between atoms of the bond $\mathrm{N}_{3} \mathrm{C}_{6}$ is smaller than that of $\mathrm{C}_{6} \mathrm{C}_{7}$ which justifies the rupture around $\mathrm{C}_{6} \mathrm{C}_{7}$ giving rise to the conjugated system, the ion $m / z 181\left(4-\mathrm{C}_{6} \mathrm{H}_{5} \mathrm{C}_{6} \mathrm{H}_{4} \mathrm{CO}^{+}\right)$. In the 10 compound the difference in density of charge between $\mathrm{N}_{3}$ and $\mathrm{C}_{6}$ is 0.175 while for $\mathrm{C}_{6}$ and $\mathrm{C}_{7}$ it is 0.345 . 
Table 4

Bond lengths in doublet state for heterocyclic ring for compounds 1-9

\begin{tabular}{lccccc}
\hline $\mathrm{N}^{\circ}$ & $\mathrm{S}_{1}-\mathrm{C}_{2}$ & $\mathrm{C}_{2}-\mathrm{N}_{3}$ & $\mathrm{~N}_{3}-\mathrm{C}_{4}$ & $\mathrm{C}_{4}-\mathrm{C}_{5}$ & $\mathrm{C}_{5}-\mathrm{S}_{1}$ \\
\hline $\mathbf{1}$ & 1.926 & 1.378 & 1.399 & 1.399 & 1.795 \\
$\mathbf{2}$ & 1.926 & 1.378 & 1.399 & 1.400 & 1.795 \\
$\mathbf{3}$ & 1.926 & 1.378 & 1.399 & 1.400 & 1.795 \\
$\mathbf{4}$ & 1.927 & 1.378 & 1.399 & 1.400 & 1.795 \\
$\mathbf{5}$ & 1.929 & 1.379 & 1.396 & 1.398 & 1.801 \\
$\mathbf{6}$ & 1.927 & 1.378 & 1.398 & 1.398 & 1.795 \\
$\mathbf{7}$ & 1.928 & 1.379 & 1.397 & 1.397 & 1.799 \\
$\mathbf{8}$ & 1.925 & 1.378 & 1.398 & 1.401 & 1.798 \\
$\mathbf{9}$ & 1.927 & 1.378 & 1.398 & 1.400 & 1.798 \\
\hline
\end{tabular}

The mechanism of the degradation pattern of the heterocyclic ring $\mathrm{S}_{1} \mathrm{C}_{2} \mathrm{~N}_{3} \mathrm{C}_{4} \mathrm{C}_{5} \mathrm{~S}_{1}$ for $(\mathrm{Z})$ arylidene thioxobenzyl thiazolidinones 1-9 compounds leading to the formation of either the $\alpha$ - or the $\beta$-ion is explained by initial formation of the intermediary by the rupture of the bond $\mathrm{S}_{1} \mathrm{C}_{2}$ having a greater bond length than $S_{1} C_{5}$ (see Fig. 1). The other bonds form part of a conjugated system. For compounds 10-19 the degradation pattern of the heterocyclic ring does not produce strong intensity fragments.

\section{Conclusion}

The following generalizations can be drawn from the study of electron impact mass spectra: the degradation process shows the formation of stabilized ion benzylium for arylidene benzylthioxo thiazolidinones compounds and stabilized ion biphenylacylium for arylidene thioxobiphenyloxoethyl thiazolidinone compounds. The degradation pattern is in concordance of molecular mechanic studies.

\section{References}

[1] S.L. Galdino, M.C.A. Lima, A.J.S. Goes, I.R. Pitta and C. Luu-Duc, Mass spectrometry of some benzylidene imidazolidinediones and thiazolidinediones. II - chlorobenzyl imidazolidinedione and fluoro or chlorobenzyl thiazolidinedione compounds, Spectroscopy Letters 24 (1991), 1013-1021.

[2] I.R. Pitta, C. Bosso, A.J.S. Goes, M.C.A. Lima, S.L. Galdino and C. Luu-Duc, Mass spectrometry of some benzylidene imidazolidinediones and thiazolidinediones. III - positive and negative electron impact mass spectra of chlorobenzyl imidazolidinedione or thiazolidinedione compounds, Spectroscopy Letters 25 (1992), 419-431.

[3] T. Nakamura, T. Funahashi, S. Yamashita, M. Nishida, Y. Nishida, M. Takahashi, K. Hotta, H. Kuriyama, S. Kihara, N. Ohuchi, T. Nishimura, B. Kishino, K. Ishikawa, T. Kawamoto, K. Tokunaga, C. Nakagawa, I. Mineo, F. Watanabe, S. Tarui and Y. Matsuzawa, Thiazolidinedione derivative improves fat distribution and multiple risk factors in subjects with visceral fat accumulation-double-blind placebo-controlled trial, Diabetes Res. Clin. Pract. 54 (2001), 181-190.

[4] Y. Iwata, S. Miyamoto, M. Takamura, H. Yanagisawa and A. Kasuya, Interaction between peroxisome proliferatoractivated receptor $\gamma$ and its agonists: docking study of oximes having 5-benzyl-2,4-thiazolidinedione, Journal of Molecular Graphics and Modeling 19 (2001), 536-542.

[5] M.J. Reginato and M.A. Lazar, Mechanisms by which thiazolidinediones enhance insulin action, Trends Endocrinol. Metab. 10(1) (1999), 9-13.

[6] I.R. Pitta, M.C.A. Lima, S.L. Galdino and J. Barbe, Compostos arilidenotiazolidinadiônicos com atividade hipoglicêmica, INPI, PI 0300997-1 Br, Rev. Prop. Ind. n.1695, July 01, 2003.

[7] S.S.F. Brandão, V.L. Guarda, I.R. Pitta, J. Chantegrel, M. Perrissin, V.M. Souza, S.L. Galdino, F. Thomasson, M.C.A. Lima, L.F.C.C. Leite and C. Luu-Duc, Synthesis and structural study of substituted arylideneimidazolidines and arylidenebenzothiazines, Boll. Chim. Farm. 139 (2000), 54-58. 
[8] J.F.C. Albuquerque, J.A. Rocha Filho, S.S.F. Brandão, M.C.A. Lima, E.A. Ximenes, S.L. Galdino, I.R. Pitta, J. Chantegrel, M. Perrissin and C. Luu-Duc, Synthesis and antimicrobial activity of substituted imidazolidinediones and thioxoimidazolidinones, Il Farmaco 54 (1999), 77-82.

[9] T.G. Silva, F.S.V. Barbosa, S.S.F. Brandão, M.C.A. Lima, L.F.C. Leite, S.L. Galdino, I.R. Pitta and J. Barbe, Synthesis and structural elucidation of new benzylidene imidazolidines and acridinylidene thiazolidines, Heter. Comm. 7(6) (2001), 523-528.

[10] A.M.C. Andrade, W.T. Lima, M.P.A. Rocha, M.C.A. Lima, S.L. Galdino, J.M. Barbosa Filho, A.J.S. Góes and I.R. Pitta, Synthesis and structural study of substituted thioxothiazolidinones and thioxoimidazolidinones, Boll. Chim. Farmac. 141(6) (2002), 428-433.

[11] J.F.C. Albuquerque, A.M.C. Andrade, A.L.M. Barros, M.R. Nascimento, E.A. Ximenes, S.L. Galdino and I.R. Pitta, Thiazolidinediones et thioxothiazolidinones substitués: synthèse et étude structurale, Ann. Pharm. Fr. 57 (1999), 385391.

[12] S.S.F. Brandão, J.A. Rocha Filho, J. Chantegrel, J.F.C. Albuquerque, E.A. Ximenes, S.L. Galdino, I.R. Pitta, M. Perrissin and C. Luu-Duc, Synthèse et structure des arylazo-imidazolidines et arylidènethiazolidines substituées, Ann. Pharm. Fr. 55 (1997), 206-211.

[13] F.W. McLafferty, Mass spectrometry analysis. Aromatic halogenated compounds, Anal. Chem. 34 (1962), 16. 


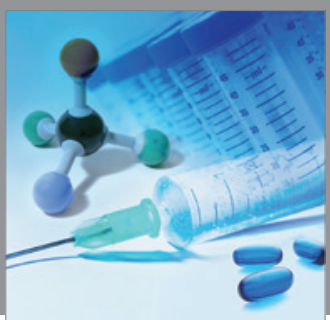

International Journal of

Medicinal Chemistry

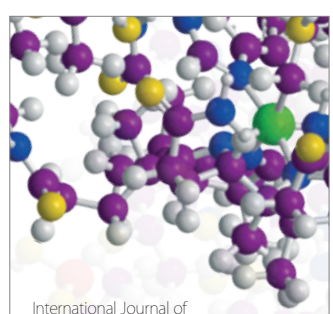

Carbohydrate Chemistry

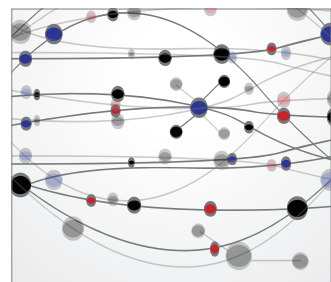

The Scientific World Journal
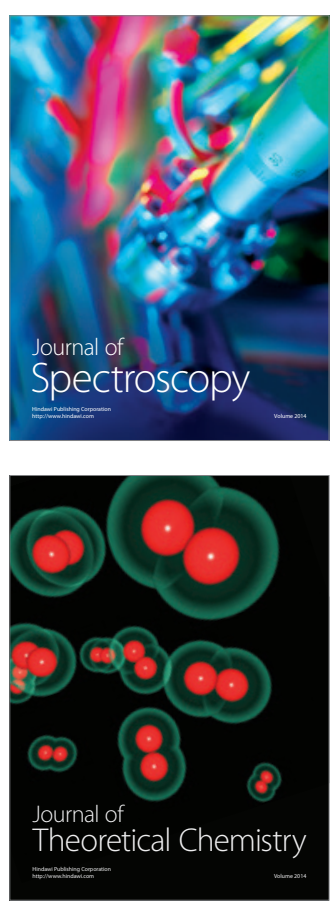
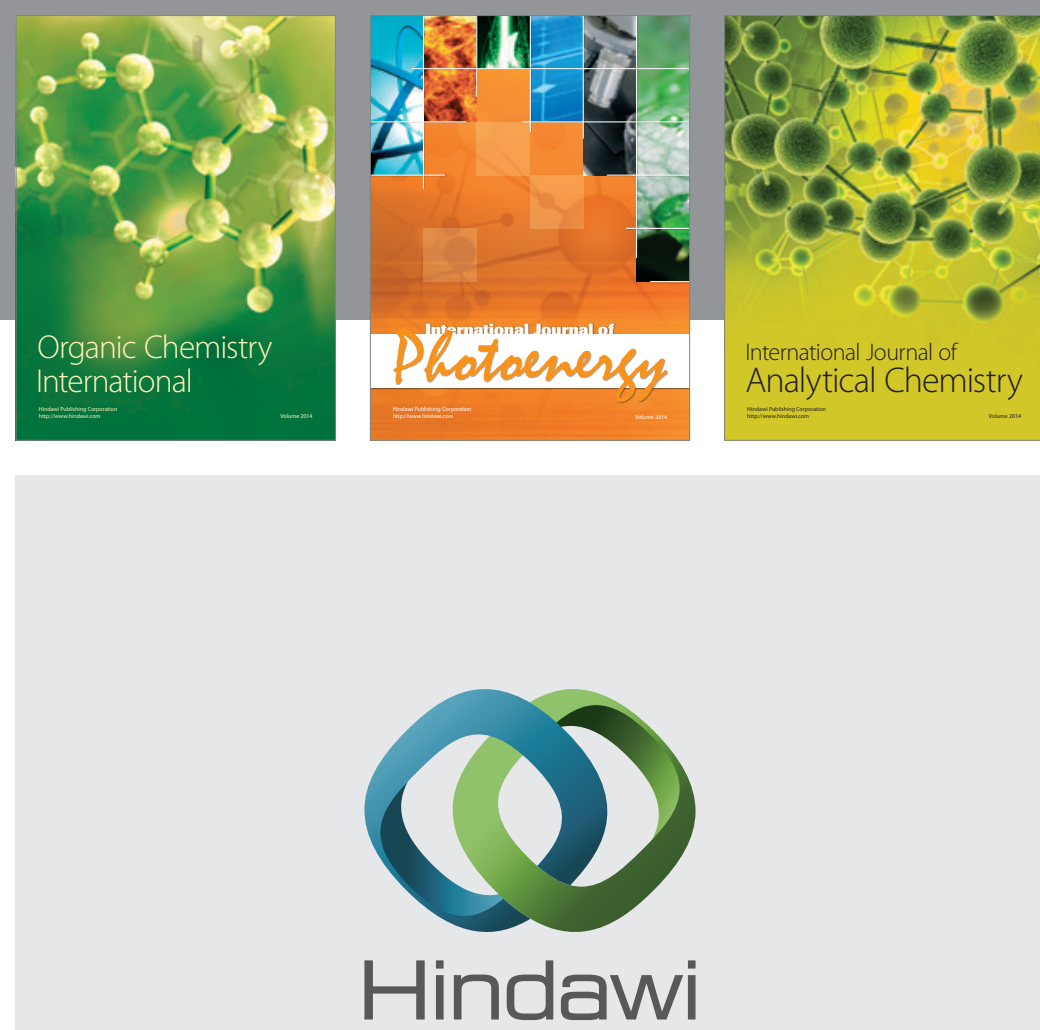

Submit your manuscripts at

http://www.hindawi.com
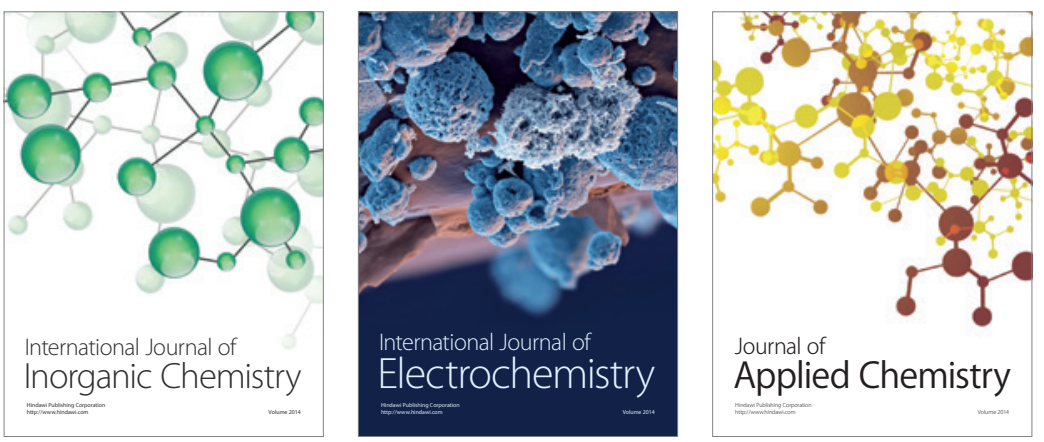

Journal of

Applied Chemistry
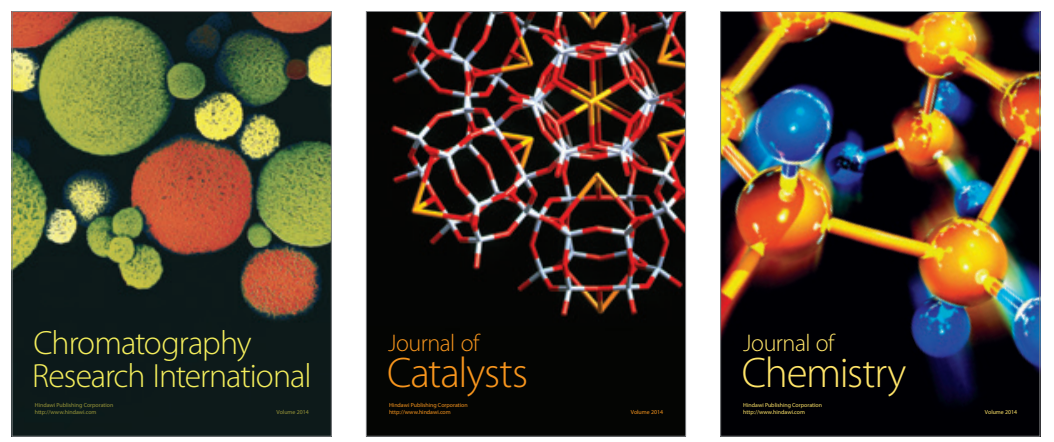
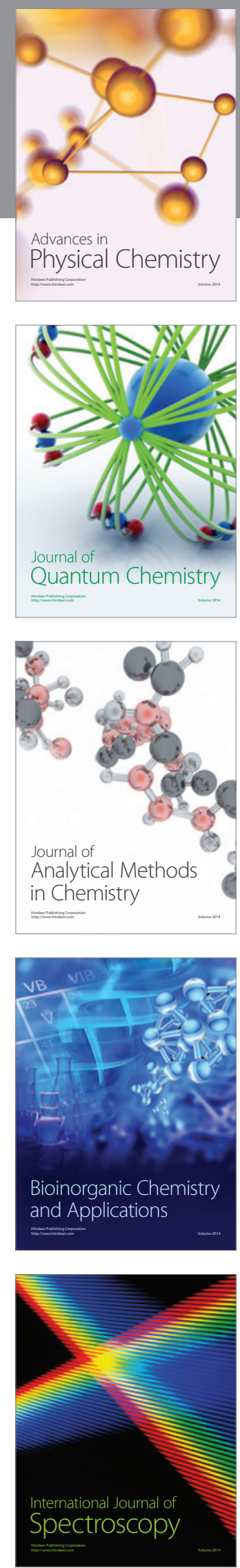